\title{
Knowledge, Beliefs and Practices of People diagnosed with Type- 1 Diabetes towards Diabetes Mellitus and Diabetic Foot Syndrome
}

\author{
Shiju Raman Unni ${ }^{1 *}$, Hani Naguib ${ }^{1}$, Mary Mccallum ${ }^{2}$ \\ ${ }^{1}$ Department of Internal Medicine, Endocrine \& Diabetes, Al Nahdha Hospital, Oman. \\ ${ }^{2}$ Health psychologist, 10 Broom Park, Aberdeen, UK.
}

*Corresponding Author: Shiju Raman Unni, Department of Internal Medicine, Endocrine \& Diabetes, Al Nahdha Hospital, Oman.

Received Date: September 20, 2021; Accepted Date: December 28, 2021; Published Date: January 05, 2022

Citation: Shiju Raman Unni, Hani Naguib and Mary Mccallum, (2022). Knowledge, Beliefs and Practices of People diagnosed with Type-1 Diabetes towards Diabetes Mellitus and Diabetic Foot Syndrome. J. Diabetes and Islet Biology, 5(1); DOI:10.31579/2641-8975/025

Copyright: () 2022 Shiju Raman Unni this is an open-access article distributed under the terms of the Creative Commons Attribution License, which permits unrestricted use, distribution, and reproduction in any medium, provided the original author and source are credited.

\section{Abstract}

Background: Diabetes Mellitus (DM) is associated with significant morbidity and mortality. Diabetic foot syndrome is one of the most common devastating preventable complications of diabetes mellitus (DM).

Objectives: We aimed to evaluate the knowledge, Beliefs and Practices (KBP) among Omani patients with type 1 diabetes mellitus (T1DM) regarding DM and Diabetes foot.

Design: A cross sectional descriptive study was used.

Settings: A secondary care, polyclinic named Bawshar in Muscat, Oman where patients were seen three days per week.

Sample Size: A convenient sample of 100 participants between age group 16 to 30 years were involved.

Materials and methods: A validated semi- structured questionnaire was used to assess KBP of T1DM with six domains. During the study period from November 2019 to December 2019. .The data was analysed by using Statistical Package for the Social Sciences (SPSS) Statistics Inc., Chicago, US version 20.

Results: There were 50 females, 50 males; $5 \%$ of patients were illiterate and $30 \%$ of them were working. $65 \%$ were students. Only $50 \%$ checked their foot regularly and only $55 \%$ check there blood glucose regularly $.57 \%$ don't know the cause of diabetes, $25 \%$ don't know the complications of the same while $20 \%$ don't know cause of diabetic foot and $25 \%$ don't know the symptoms of diabetic foot. $20 \%$ beliefs checking blood glucose is the responsibility of the doctor and $85 \%$ beliefs walking bare foot is high risk factor for DM foot.

Conclusions: In reality healthcare providers must be trained to counsel people with DM to plan adequate interventions that enable an understanding of the offered information. A well-structured ,Behaviour change counselling (BCC) like Motivational interviewing (MI)are considered the ideal practices for this patients, to prevent DM complications.

Limitations: The sample size is small and single centred study which cannot be generalised to whole Omani population.

Keywords: diabetic foot; knowledge; beliefs, practice; oman; diabetes mellitus

\section{Introduction}

The prevalence of diabetes mellitus (DM) is still increasing year by year [1] and it is estimated that the number of people with diabetes will increase 1.5 times from 463 million in 2019 to 700 million in 2045 [2] According to World health organisation data in 2019 diabetes mellitus was direct cause of 1.5million deaths. [3] The prevalence of DM in Oman has increased over the past three decades in parallel with rapid economic growth, urbanization, and changes in lifestyle behaviours. [4] According to NCD survey in Oman the prevalence of DM is $14.5 \%$. [5].

Diabetic foot syndrome (DFS) is one of the common and most devastating preventable complications of diabetes mellitus (DM). It is associated with morbidity and premature mortality due to long-term complications. Lower extremity disease, which includes foot ulceration, peripheral neuropathy, peripheral arterial disease, or amputation, is twice as common as in people with diabetes when compared with healthy 
individuals. In Oman, around half (47\%) of all lower limb amputations are performed in those with diabetes [6].

A study conducted in 2002, highlighted the importance of proper education and awareness programs in changing attitudes toward DM. The study clearly shown that diabetes education and care management can significantly improve patient outcomes, glycaemic control and quality of life a study in India found inverse relation between knowledge and diabetic foot complications, which is more the knowledge less the complications $[7,8]$.

However, a knowledge, attitude and practice gap still exists in T1DM management .Our study was conducted to assess the KBP among100 adult Omani patients with T1DM in a diabetic clinic at Bausher polyclinic. The findings of this study will help in designing effective educational program for prevention and control of this dreaded disease in Oman.

\section{Patients and Methods}

\section{Study Design:}

This cross sectional descriptive study was conducted during november 2019- december 2019 at the outpatient clinic of Basher polyclinic in Muscat region of Sultanate of Oman by using a questionnaire to evaluate the KBP of Omani patients diagnosed with T1DM.

\section{Study population:}

100 T1DM patients participated in the study. Inclusion criteria were: patients aged between 16 to 30 years who are known to have diabetes were included in the study. Exclusion criteria were 1) patients who denied consent to be part of the study. 2) Patients who already had diabetic foot syndrome, amputated foot, or foot ulcers and 3) patients with type 2 Diabetes Mellitus.

\section{Assessment tool:}

The questionnaire was combined, modified, revised and validated to better align with the Omani diabetes and Omani diabetic foot guidelines. ${ }^{13}$ the revised questionnaire covered six domains: demographic details, patient-reported diabetes-related foot disease, foot self-care, diabetes care education, foot care education, and professional foot care. A questionnaire containing 24 closed-ended and multiple choice type questions on KBP was developed to investigate the relationship between knowledge attitudes and practice of T1DM patients. The questionnaire includes knowledge of measures to prevent diabetic foot, attitudes to prevent it and self-care practices of the person with T1DM. One point was awarded for each correct answer. The questionnaire was beta-tested 5 patients to assess the validity, suitability of content, clarity and flow of questions. Necessary corrections and modifications were made based on the results of the pilot study. The questionnaire was prepared in English but prior to use in the study, was translated to Arabic. The Arabic version of the questionnaire was reviewed for language, clarity, and structure and was administered in face-to-face interviews to collect the data. (Appendix 1).

\section{Data synthesis and analysis:}

A total of 9 items were included in the knowledge section which included elementary knowledge of diabetes, benefits of exercise, complications of diabetes, prevention of diabetic foot. For the nine items knowledge question, the maximum attainable score was ' 9 ' and the minimum score was ' 0 '. Likewise, in the Belief section, a total of 8 items were included which consisted of respondents Belief towards diabetes. A 6 point Likert scale was used to measure attitude.

\section{Statistical analysis:}

Data were analysed in a database created using a Mic-rosoft Offi ce Excel $2007^{\mathrm{TM}}$ spreadsheet, and later transferred to SPSS (Statistical Package for the Social Sciences) version Policarpo NS, Moura JRA, Melo Júnior EB, Almeida PC, Macêdo SF, Silva ARV 38Rev Gaúcha Enferm. 2014 set; 35(3):36-42.17.0 To calculate statistical measurements and standard de Viation for variables addressed in the collection instrument Data were analysed in a database created using a Microsoft Offi ce Excel 2007 spreadsheet, and later transferred to SPSS (Statistical Package for the Social Sciences) version Policarpo NS, Moura JRA, Melo Júnior EB, Almeida PC, Macêdo SF, Silva ARV38Rev Gaúcha Enferm. 2014 set; 35(3):36-42.17.0 to calculate statistical measurements and standard deviation for variables addressed in the collection instrument Data were analysed in a database created using a Microsoft Offi ce Excel 2007TM spreadsheet, and later transferred to SPSS (Statistical Package for the Social Sciences) version Policarpo NS, Moura JRA, Melo Júnior EB, Almeida PC, Macêdo SF, Silva ARV38Rev Gaúcha Enferm. 2014 set; 35(3):36-42.17.0 to calculate statistical measurements and standard deviation for variables addressed in the collection instrument Data were analysed in a database created using a Microsoft Offi ce Excel 2007 spreadsheet, and later transferred to SPSS (Statistical Package for the Social Sciences) version Policarpo NS, Moura JRA, Melo Júnior EB, Almeida PC, Macêdo SF, Silva ARV38Rev Gaúcha Enferm. 2014 set;35(3):36-42.17.0 to calculate statistical measurements and standard deviation for variables addressed in the collection instrument Data were analysed in a database created using a Microsoft Offi ce Excel 2007 spreadsheet, and later transferred to SPSS (Statistical Package for the Social Sciences) version Policarpo NS, Moura JRA, Melo Júnior EB, Almeida PC, Macêdo SF, Silva ARV38Rev Gaúcha Enferm. 2014 set;35(3):36-42.17.0 to calculate statistical measurements and standard deviation for variables addressed in the collection instrument Data were analysed in a database created using a Microsoft Office Excel 2007 spreadsheet, and later transferred to SPSS (Statistical Package for the Social Sciences) version 17.0 to calculate statistical measurements and standard deviation for variables addressed in the collection instrument.

\section{Results}

\section{Profile of the study population:}

The demographic baseline characteristics of the study population are shown in Table 1. 39\% of the patients were aged between 26 to 30 years there were females $(50 \%)$ and $50 \%$ males than males. $40 \%$ of them were in college and $25 \%$ of them in higher secondary school while the remainder were educated with different levels .Nearly one quarter (30\%) were working .5\% were illiterate and $53 \%$ had diabetes for more than 10 years (Table-1)

\begin{tabular}{|l|l|l|}
\hline Characteristics & Number & Percentage \\
\hline Age (year): & 23 & 23 \\
\hline $16-20$ & 38 & 38 \\
\hline $20-25$ & & \multicolumn{2}{|l|}{} \\
\hline
\end{tabular}




\begin{tabular}{|c|c|c|}
\hline $26-30$ & 39 & 39 \\
\hline \multicolumn{3}{|l|}{ Educational level: } \\
\hline Illiterate & 5 & 5 \\
\hline Higher Secondary School & 25 & 25 \\
\hline University & 40 & 40 \\
\hline working & 30 & 30 \\
\hline \multicolumn{3}{|c|}{ Duration of diabetes (Years): } \\
\hline Less 10 & 47 & 47 \\
\hline $10-20$ & 53 & 53 \\
\hline \multicolumn{3}{|l|}{ Family history of diabetes: } \\
\hline Yes & 34 & 34 \\
\hline No & 66 & 66 \\
\hline
\end{tabular}

Table 1. Demographic and socioeconomic characteristics of the study participants.

\section{Knowledge:}

Out of 100 subjects, $57 \%$ did not know the causes of diabetes $.85 \%$ of subjects knows the 'normal' blood glucose values. $20 \%$ of subjects did not know the causes of diabetic foot syndrome and one-fourth $(25 \%)$ of the subjects did not know symptoms of diabetic foot syndrome. Just over one-fifth $(25 \%)$, thought that their doctor alone was responsible for foot examination $25 \%$ did not know about diabetes complications $36 \%$ did not know how to prevent diabetic foot syndrome, $24 \%$ did not know risk factors that cause the disease. Only $40 \%$ thought they should examine their own feet. (Figure $1 \&$ Table-2).

\section{Beliefs:}

The majority acknowledged that walking barefoot and that "diabetic foot syndrome" are big problems $85 \%$ and $90 \%$ respectively. $80 \%$ subjects accepted that patients with diabetes cannot eat everything even if they are compliant with medications. One-fifth (20\%) thought that checking their blood sugar was the responsibility of their doctor only. Smaller proportions of respondents believed that diabetes cannot be fully treated (25\%) and that uncontrolled diabetes is not serious (7\%). (Figure1\& Table-2).

\section{Practices:}

$60 \%$ of subjects reported they were checking water temperature before its use, $80 \%$ denied walking barefoot, and $64 \%$ stated that they check with their doctor if they have a foot problem. Moreover, 50\% stated that they have been physically active and $40 \%$ reported physical activity 5 times a week .Furthermore, 50\% reported drying their feet after washing, 60\% use warm water for washing feet, $38 \%$ check their feet regularly. Finally, more than haif 55\% confirmed checking their blood sugar regularly. (Figure1 \& Table-2). 


\begin{tabular}{|l|l|}
\hline \multicolumn{2}{|c|}{ Knowledge section } \\
\hline Those who Don't know Cause of diabetes & $57 \%$ \\
\hline Don't know Risk Factor that can lead to diabetes & $24 \%$ \\
\hline Don't know Complications of diabetes & $25 \%$ \\
\hline Those who has Knowledge of Normal blood sugar level & $85 \%$ \\
\hline Those who knows knowledge of Cause of diabetic foot & $80 \%$ \\
\hline Those who knows knowledge of symptoms of Diabetes & $75 \%$ \\
\hline Those who belief doctor is responsible for examining feet & $20 \%$ \\
\hline Those who knows examining feet daily is important & $40 \%$ \\
\hline Those who don't know how to prevent diabetes foot & $36 \%$ \\
\hline
\end{tabular}

\begin{tabular}{|l|l|}
\hline \multicolumn{2}{|c|}{ Beliefs section } \\
\hline Uncontrolled blood sugar will not do harmful & $7 \%$ \\
\hline Checking blood sugar is responsibility of doctor only & $20 \%$ \\
\hline Cannot be treated for diabetes completely & $25 \%$ \\
\hline Having diabetic foot is a serious problem & $90 \%$ \\
\hline Walking foot has serious impact on diabetic patient & $85 \%$ \\
\hline $\begin{array}{l}\text { Diabetic patient can eat what he wants if he is compliant well with } \\
\text { medication }\end{array}$ & $20 \%$ \\
\hline
\end{tabular}

\begin{tabular}{|l|l|}
\hline \multicolumn{2}{|c|}{ Practice section } \\
\hline Check blood sugar regularly & $55 \%$ \\
\hline Check with the doctor if there is foot problem & $64 \%$ \\
\hline I inspect my feet regularly & $50 \%$ \\
\hline I use warm water to wash my feet & $60 \%$ \\
\hline I use towel to dry up my feet and inter digital spaces & $50 \%$ \\
\hline I don't walk bare foot & $80 \%$ \\
\hline I do exercise regularly & $50 \%$ \\
\hline I will check water temperature before use & $60 \%$ \\
\hline
\end{tabular}

Table 2 Results of Knowledge ,Beliefs and Practice 


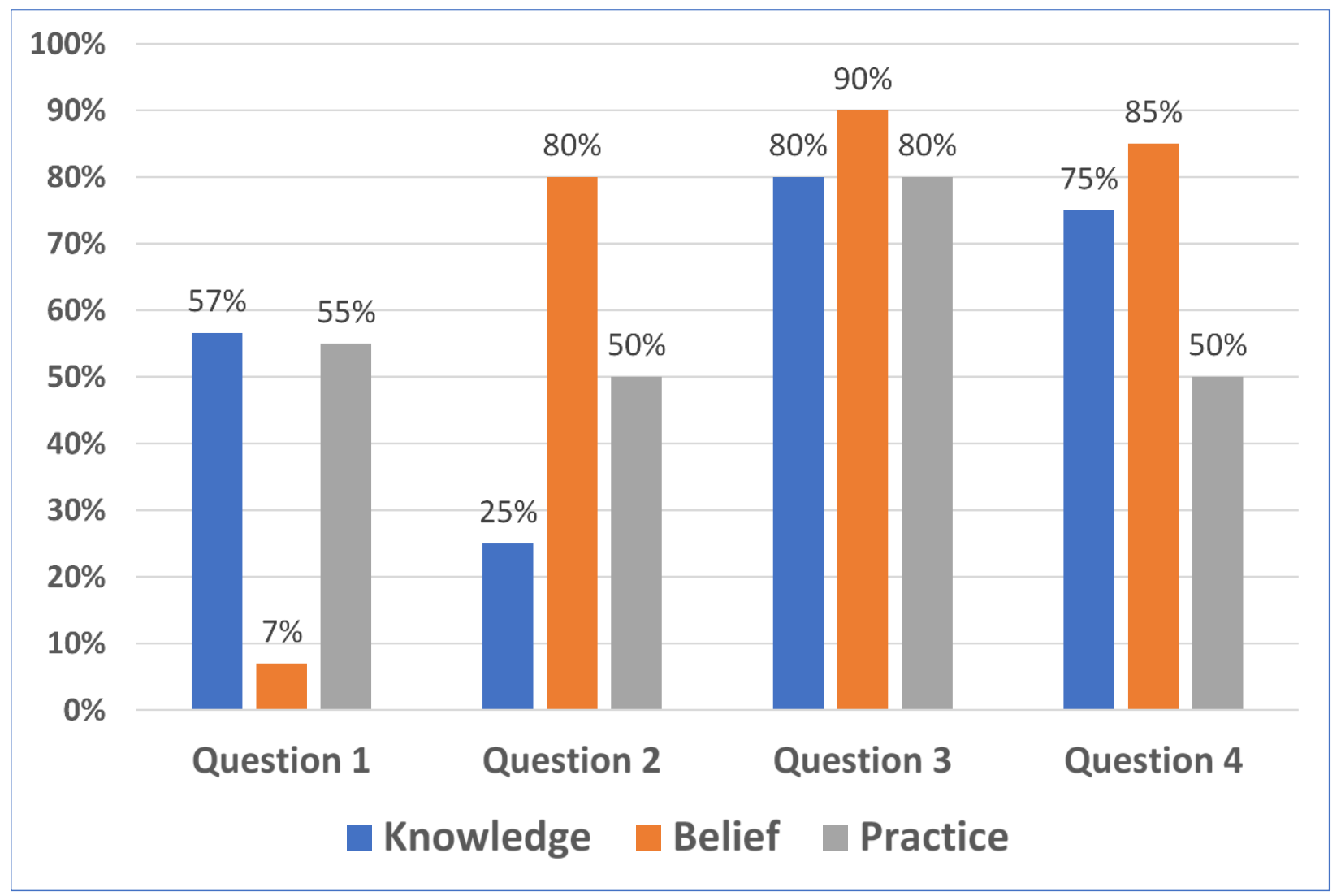

\begin{tabular}{|l|l|l|l|}
\hline $\mathbf{Q}$ & \multicolumn{1}{|c|}{ Knowledge } & \multicolumn{1}{c|}{ Beliefs } & \multicolumn{1}{c|}{ Practice } \\
\hline 1 & Don't know Causes of DM & $\begin{array}{l}\text { Believes that uncontrolled DM is } \\
\text { not serious }\end{array}$ & $\begin{array}{l}\text { Regularly checking their } \\
\text { blood sugar }\end{array}$ \\
\hline 2 & $\begin{array}{l}\text { Don't know } \\
\text { Complications of DM }\end{array}$ & $\begin{array}{l}\text { Believes that checking blood } \\
\text { sugar is the responsibility of } \\
\text { doctor only }\end{array}$ & Checking their feet regularly \\
\hline 3 & $\begin{array}{l}\text { Don't know Causes of } \\
\text { Diabetic foot }\end{array}$ & $\begin{array}{l}\text { Agree that Diabetic foot is a } \\
\text { major problem }\end{array}$ & DO NOT walk bare foot \\
\hline 4 & $\begin{array}{l}\text { Don't know Symptoms of } \\
\text { Diabetic foot }\end{array}$ & $\begin{array}{l}\text { Agree that walking bare foot } \\
\text { carries high risk }\end{array}$ & Dry their foot after walking \\
\hline
\end{tabular}

Figure-1 Bar Graph showing results of of Knowledge Beliefs and Practice questionnare

\section{Discussion}

Knowledge is an essential requirement for better compliance with medical therapy.It is a hypothesis that good KBP have impact on adequate diabetes control. Even though $40 \%$ of subjects were studying in university and $30 \%$ of subjects is working, they had insufficient knowledge regarding the symptoms, complications, prevention and control of their disease condition. Awareness of complications of diabetes was not good among the patients in this study. $57 \%$ of the patients in our study did not know the cause of DM; $25 \%$ did not know about diabetes complications; $20 \%$ don't know the cause of diabetic foot syndrome; $25 \%$ don't know about symptoms of diabetic foot .Several studies in India observed an inverse relationship between diabetic foot ulcer and foot care knowledge as well as practice as seen in our study also. [9, 10, 11, 12 \&13]. While, another study in England as a developed country, also stated poor knowledge of diabetes among ethnic groups [14].

In our study, overall, it was found that T1DM patients had insufficient knowledge regarding the symptoms, complications, prevention and control of their disease condition. However, a study from Malaysia reported a good knowledge, attitude and practice score among diabetic patients [15] .The differences in the results of studies may be due to the differences in educational level of the diabetic patients and accessibility of information and diabetes education. It is well established that patient contributions are very important for better management of diabetes. 
In terms of attitude/beliefs a considerable disposition to practice selfexamination and self-care was detected Although $85 \%$ agreed that walking bare foot carries high risk for development of diabetic foot complications $7 \%$ believe DM is not a serious problem and one-fourth (25\%) still believed DM is not fully treatable. However in relation to practice, there is significant gaps were observed only 55\% regularly monitoring blood glucose levels and only 50\% checking feet daily regularly Only 50\% were engaged in exercise. This finding could be related to a lack of knowledge and lack of organized diabetes education services in the diabetes clinic. Our findings indicate that knowledge, beliefs and practices must be interconnected in order to achieve successful preventive foot care.

Awareness of complications of diabetes was not good among the patients in this study. This may be due to the some factors such as inappropriate ways of providing information and lack of time due to the patient loads and lack of continuity in education by health care providers. A study in Nigeria observed that foot care and education to prevent complications were least suggested by doctors.[16] It has been also reported in a study from Pakistan that appropriate educational program can have effect on the attitude of the people about diabetes [17]. Another study showed that serious diabetes education can improve glycaemic control and quality of life of diabetic patients $[18,19]$.This recommends the necessity for an awareness program, patient counselling and education on self-care management of the diabetic patients to improve their knowledge regarding diabetes with the emphasis on lifestyle modifications, and this process should be continuous not only in primary set up but also in any level of management the patient will go to and also not only for health educators but all who offer the service should share in this process.

Is it only patient who is responsible or HCPs also need to be addressed as care givers especially in such low educational level patients. ? Therefore, a joint effort on part of the health care professionals and the patient is required to provide and receive education, respectively, about foot care so as to reduce foot problems. Our study reveals the importance of self-care which is mainly aimed for normal function, development, health, and well-being of the patient. However, the lack of knowledge due to low education status and the lack of timely information provided by the caring physician to the patient need to be analysed deeply.

Our study revealed a medium level of knowledge, belief and practice for the majority of T1DM patients in basher polyclinic. T1DM patients usually are dependent on insulin for disease control while ignoring other healthy lifestyle modifications in practice. Low awareness about the diabetes among T1DM patients, affects their ability of self-management and therefore have a negative impact on outcome of diabetes. What we really need is dialogue with the patient utilizing a Behaviour Change Counselling (BCC )such as motivational interviewing (MI) approach which works on the philosophy that the patient and health care professional must work together to explore the difficulties of changing foot care management in a non-judgmental approach. This is achieved by the use of open ended questions, reflection and summary with clear goals and specific strategies to develop a commitment to change and ensure this belief is translated to practice.

\section{Limitations}

The sample size is small and single centred study, so the findings of the study cannot be generalized to the all diabetes mellitus subjects in Oman. Multi centred study with larger sample size from different institutions will enhance the generalizability of the findings for future studies.

\section{Conclusions}

This study revealed a suboptimal level of KBP for the majority of T1DM patients in the study population, who usually are dependent on drugs for disease control while ignoring practical lifestyle modifications. Lack of awareness about diabetes among patients, affects their ability to selfmanage and therefore has a negative impact on outcomes. We need a structured, well designed behaviour counselling and interviews by health care workers.

\section{Recommendation}

We recommend the ministry of health, Oman to implement continuous awareness program, counselling and education on self-care management of patients with diabetes mellitus such as BCC, Motivational interviewing involving both patients and health care professional together to explore the difficulties of changing diabetes and foot care management to improve their knowledge regarding diabetes mellitus with the emphasis on lifestyle modifications.

\section{Acknowledgments}

The authors are grateful to Dr. Thamra al Ghafry (DG,Muscat) for inspiring, editing, and proofreading, and also for Dr. Hanan al Mahrooqi (Bausher polyclinic) for support. We are also grateful to Dr. Hamad al Harthy and Dr. Mohamed al Hinaii (Alnahda Hospital) for continued support during the study.

\section{Authors' contributions}

All authors contributed to the conception, conduct of the study. They contributed to the drafting, revision, and final approval of the manuscript.

\section{Funding and sponsorship}

None

\section{Conflict of interest}

The author declares that there is no conflict of interests.

Compliance with ethical principles Institutional approval and informed written consent was obtained from all respondents.

\section{References}

1. World Health Organization, Diabetes: Key facts [Internet]. World Health Organization; 2020.

2. Saeedi P, Petersohn I, Salpea P, Bright D, Williams R, On behalf of the IDF Diabetes Atlas Committee. Global and regional diabetes prevalence estimates for 2019 and projections for 2030 and 2045: results from the international diabetes federation diabetes atlas, 9th edition. Diabetes Res. Clin. Pract. 2019;157:110

3. https://www.who.int/news-room/fact-sheets/detail/diabetes april 2021

4. Al-Lawati JA, Panduranga P, Al-Shaikh HA, Morsi M, Mohsin N, Khandekar RB, et al. Epidemiology of diabetes mellitus in Oman: results from two decades of research. Sultan Qaboos Univ Med J 2015. May;15(2):e226-e233.

5. https://mohcsr.gov.om/wpcontent/uploads/2019/01/ExecutiveSu mmary_NCDsurvey2017_En.pdf

6. Al-Busaidi IS, Abdulhadi NN, Coppell KJ. Care of patients with diabetic foot disease in Oman. Sultan Qaboos Univ Med J 2016 Aug; 16(3):e270-e276.

7. Ibrahim S. Al-Busaidi, Nadia N. Abdulhadi and Kirsten J. Coppell Development and Pilot Testing of a Diabetes Foot Care and Complications Questionnaire for Adults with Diabetes in Oman: The Diabetic Foot Disease and Foot Care Questionnaire Oman Medical Journal [2020], Vol. 35, No. 4: e146

8. Development and Pilot Testing of a Diabetes Foot Care and complications Questionnaire for Adults with Diabetes in Oman: The Diabetic Foot Disease and Foot Care Questionnaire original article O MJ [2020], V. 35, N. 4: e146 chellan G, 
Srikumar S, Varma AK, et al. Foot care practice - the key to prevent diabetic foot ulcers in India. Foot (Edinb). 2012;22(4):298-302

9. Al-Hariri MT, Al-Enazi AS, Alshammari DM, Bahamdan AS, AlKhtani SM, Al-Abdulwahab AA. Descriptive study on the knowledge, attitudes and practices regarding the diabetic foot. J. Taibah Univ. Med. Sci. 2017;12(6):492-496.

10. George H, Rakesh P, Krishna M, Alex R, Abraham VJ, George K, et al. Foot care knowledge and practices and the prevalence of peripheral neuropathy among people with diabetes attending a secondary care rural hospital in Southern India. J Family Med Prim Care. 2013; 2:27-32.

11. Chellan G, Srikumar S, Varma AK, Mangalanandan TS, Sundaram KR, Jayakumar RV, et al. Foot care practice - The key to prevent diabetic foot ulcers in India. Foot (Edinb) 2012; 22:298-302.

12. Policarpo NDS, Moura JRA, Melo Júnior EBD, Almeida PCD, Macêdo SFD, Silva ARVD. Knowledge, attitudes and practices for the prevention of diabetic foot. Rev Gaucha Enferm. 2014;35(3):36-42.

13. Singh RP, Khobragade M, Anil K. The knowledge, attitude and practices among diabetic patients about diabetes and it complications in Central Delhi. MRIMS J Health Sci. 2013; 1:4447.
14. Baradaran H, Knill-Jones R. Assessing the knowledge, attitudes and understanding of type 2 diabetes amongst ethnic groups in Glasgow, Scotland. Practical Diabetes Int. 2004; 21 (4): 143-148.

15. Ambigapathy R, Ambigapathy S, Ling H. A knowledge, attitude and practice (KAP) study of diabetes mellitus among patients attending Klinik Kesihatan Seri Manjung. NCD Malaysia. 2003; 2 (2): 6-16.

16. Ekore RI, Ajayi IO, Arije A, Ekore JO. Knowledge of and attitude to foot care amongst Type 2 diabetes patients attending a university-based primary care clinic in Nigeria. Afr J Prim Health Care Fam Med. 2001; 2:3.

17. Badrudin N, Basit A, Hydrie MZI, Hakeem R. Knowledge, Attitude and Practices of patient visiting a diabetes care unit. Pak J Nutrition. 2002; 1(2):99-102.

18. Maina WK, Ndegwa ZM, Njenga EW, Muchemi EW. Knowledge, Attitude and Practices related to Diabetes among Community Members in Four Provinces in Kenya: A Crosssectional study. Journal of Pan African Medical. 2011; 7 (2): 1-9

19. Khanna A, Bush AL, Swint JM, Peskin MF, Street Jr RL, Naik AD. Hemoglobin A1C improvements and better diabetes-specific quality of life among participants completing diabetes selfmanagement programs: a nested cohort study. Health and Quality of Life Outcomes.2012; 10 (1): 48:1-7 
Appendix1questionnare

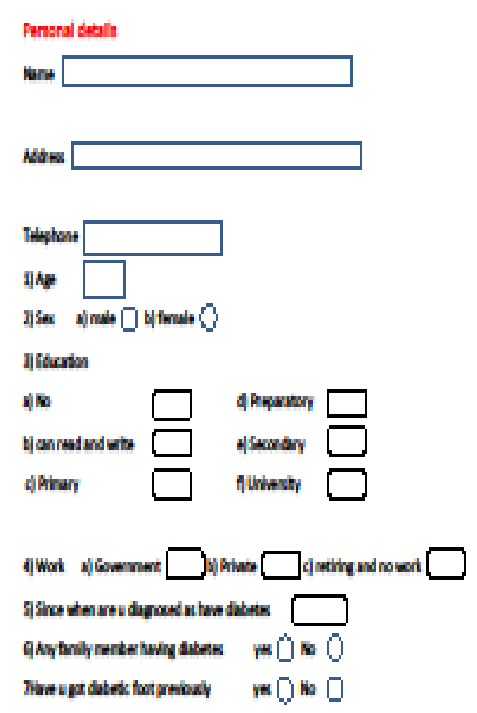

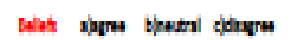

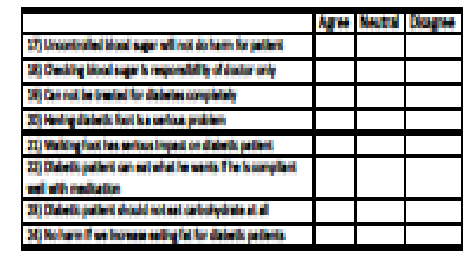

PRACTICE

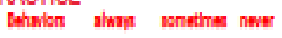

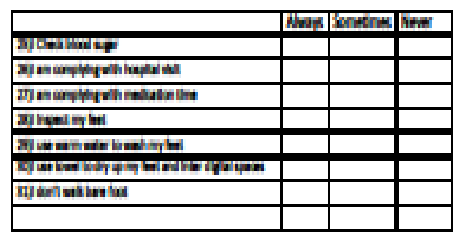

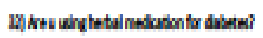

s) Ondy uinghutals

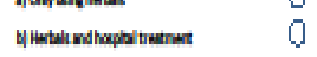

QDontuobitit

Q

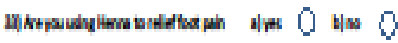

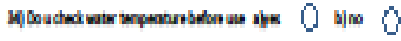

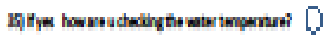

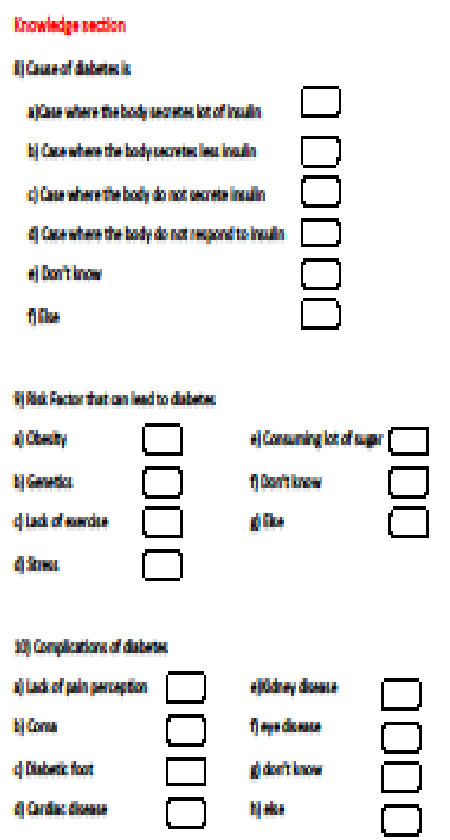

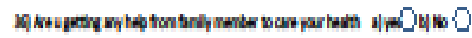

17) Warind of

1) romind pos

bi hapas hathy fod

4 cie nudato

A dasaphy

if the

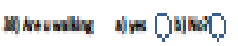

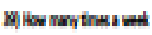

i) $\mathrm{h}$

เ) 15

467

A donapph

$\square$
$\square$
$\square$

4) low byasumatic

Nisutan Mnith

เท Yman

q northen 10 nin

Gibnewily

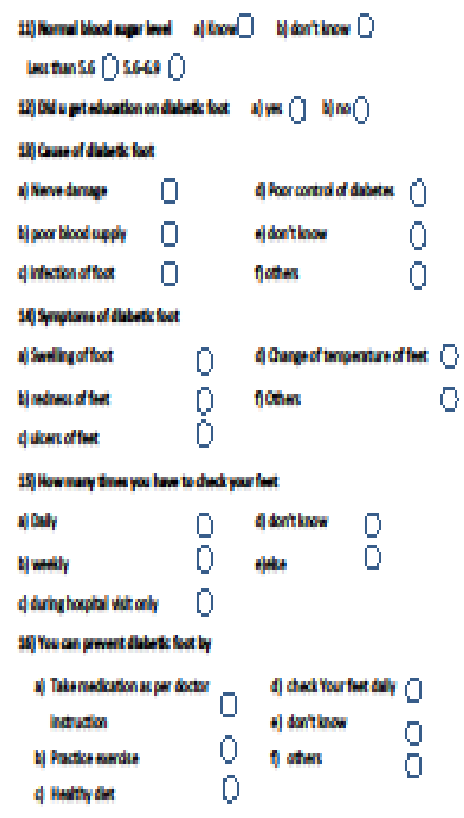

